\title{
Allelopathic effect of some plants on morphological attributes of invasive alien weed: Malachra capitata (L.)L.
}

\author{
Ramgunde Vaishali * and Chaturvedi Alka \\ Department of Botany, Rashtrasant Tukadoji Maharaj Nagpur University, Nagpur, Maharashtra, India.
}

Publication history: Received on 06 February 2019; revised on 23 February 2019; accepted on 27 February 2019

Article DOI: https://doi.org/10.30574/gscbps.2019.6.2.0020

\begin{abstract}
Vitex negundo L. [Verbenaceae] and Ricinus communis L. [Euphorbiaceae], are especially well known for their industrial, pharmacological, and toxicological properties, but to date very little is known about their allelopathic potential. Hence the present study was conducted to evaluate their allelopathic perspectives on morphological characters of invasive alien weed Malachra capitata [L.]L. Various concentrations [T1=5\%, T2=10\%, T3=15\% and T=20\%] of leaf leachates of selected plants were used as spray to test their effect on pot culture of test species. Results of present study indicated that the growth of plant was significantly inhibited in Malachra at all concentration of aqueous leaf leachates of selected plants when compared to control [T0]. Length of root and shoot, number of flowers, fruits and seeds of the weed was reduced with the increase in leaf leachates concentration. T1 of $R$. communis was least effective on root length. Branching was totally inhibited except for T1 of $V$. negundo. Dry weight and fresh weight of the weed were also negatively affected by aqueous leaf leachates of both the plants. Although results were significant at $\mathrm{P}<0.05$ level, few parameters were not found significant.
\end{abstract}

Keywords: Allelopathic potential; Invasive alien weed; Malachra capitata [L.]L.; Vitex negundo L.; Ricinus communis L.

\section{Introduction}

Weeds are known to be the main constraint to agriculture production all over the world. Invasive nonnative plant species are causing enormous economic and ecological damage. Worldwide estimation of economic damage from invasive species totals more than $\$ 1.4$ trillion, which is about $5 \%$ of the global economic loss [1]. Various common methods to control invasive weeds are mechanical, chemical and biological control. Mechanical method needs lot of man power and is laborious. Burning, as a control strategy too has proved to be inadequate because it requires large quantity of fuel and destroys all other economically important plants growing in its vicinity [2-3]. While the primary use of herbicides (Chemical control) is to control weeds in agricultural land, throughout the world herbicides are a common management tool used to control invasive species. Globally, most recent cases of herbicide resistant weeds are 476, with weeds resistance to 23 of the 26 known herbicide sites of action and to 161 different herbicides. Herbicide resistant weeds have been reported in 90 crops in 66 countries [4]. Moreover, using herbicides as a control method may have many disadvantages such as rise in environmental pollution, hazardous effects on agricultural products and costly affair. These chemicals can be replaced by low cost and environment friendly agents. Biological management through the use of suppressive plants or by authorized release of insects or pathogens as specific biological control agents is the new management option. To control weeds, biological control agents mainly from animal kingdom are regarded as relatively safe. At the same time impact of these agents can be low and unpredictable so it may be time consuming and cannot be overlooked. Although plants can be considered as biological control agents, data available only on animals as control agent, hence there remains a gap in utilizing control agents from plant kingdom to check the problem of invasion. Use

\footnotetext{
${ }^{*}$ Corresponding author

E-mail address: vramgunde@gmail.com
} 
of microbes or insects as control agents may lead to diseases or entry of new pathogens in plant kingdom while use of widely spread native or non-native plants as control agent for invaders can have additive benefits like maintenance of soil quality, balanced resource cycling and ecofriendly approach. In recent years, therefore, new approaches like plant allelopathic effects have been considered to suppress weeds in agricultural systems [5] as well as same can be employed for the control of invasive weeds.

For present study Malachra capitata (hereafter it will be referred as M. capitata) is a native of Tropical America [6], belonging to family Malvaceae was selected on the basis of field observations. Although review of literature did not show much of studies on its invasiveness and allelopathy but it was found growing luxuriantly in moist places, gardens, forest, wasteland and in agricultural field. Malachra capitata (L.)L. is listed as invasive alien plant species in the catalogue of invasive alien flora of India [7].

In recent times to control weeds either directly or as natural herbicides developed from allelochemicals isolated from allelopathic plants particularly those with medicinal properties have been gaining interest [8]. Ricinus communis L. [hereafter it will be referred as R. communis] is a plant belonging to Euphorbiaceae, commonly found in the tropical and temperate climates of the world [9-10], which is well known for many of its medicinal and industrial uses [11-12]. Vitex negundo L. [hereafter it will be referred as V. negundo] an aromatic shrub belonging to verbenaceae widely known for its use as green manure, medicine in ayurvedic, unani systems of medicine and as a mosquito repellent.

Most of the allelopathic studies were carried out in petriplates and in laboratory conditions, but it is equally important to test the extracts in soil or as foliar spray in pot culture. This study was conducted to investigate the allelopathic potential of different concentrations of aqueous leaf leachates of $V$. negundo and $R$. communis on the vegetative and reproductive attributes of alien invader $M$. capitata and an attempt has been made to find out alternate ecofriendly approach for weed management.

\section{Material and methods}

\subsection{Seeds collection of test plant}

Mature seeds of $M$. capitata were collected from the University campus; Rashtrasant Tukadoji Maharaj Nagpur University, Nagpur, India.

\subsection{Collection and extraction of plant materials}

Leaves of $V$. negundo and $R$. communis were collected from the field during the full growing stage and washed with tap water followed by shade drying. Leaf leachates were prepared by using method given by Ghayal et al., [13] wherein the dried leaves were powdered and $100 \mathrm{~g}$ powder was soaked in $1000 \mathrm{ml}$ distilled water for 24 hours at $25 \pm 2{ }^{\circ} \mathrm{C}$ and the leachates was filtered through Buchner funnel using filter paper. It was stored in amber colored bottles to avoid degradation. Various concentration [T1=5\%, T2=10\%, T3=15\% and T4=20\%] of leaf leachates were prepared. Leaf residue was prepared by grinding air dried leaves of selected plants to powder form with a grinder and kept in sealed polythene bags to prevent it from moisture and contamination [14].

\subsection{Pot culture}

Polythene bags [ $35 \mathrm{~cm}$ X $25 \mathrm{~cm}$ size] were filled with $5 \mathrm{~kg}$ soil mixture [soil: sand in 3:1 ratio] and $100 \mathrm{~g}$ leaf residue was also mixed in top layer of soil. Bags were sown with 20 seeds of test species and were thinned to 3 healthy seedlings per bag after7-10 days of sowing. With the emergence of first leaf, seedlings were sprayed with various leaf leachates concentration $[\mathrm{T} 1=5 \%, \mathrm{~T} 2=10 \%, \mathrm{~T} 3=15 \%$ and $\mathrm{T} 4=20 \%$ of respective leaf leachates] with equal quantity per plant. Spraying of leaf leachates was carried out till the flowering at the interval of 10 days. The control polythene bags were sprayed with water [ $\mathrm{T} 0=$ control]. Various growth parameters were recorded at vegetative and reproductive stage by considering five plants per treatment. Fresh weight and dry weight of root and shoot were also recorded by uprooting the plants. Experiment was repeated consecutively for three years with three replications to measure various parameters as within one season all parameters were not possible to measure.

\subsection{Statistical analysis}

Data generated from present investigation was analyzed statistically by using SPSS version 17 [SPSS incorporation]. One way ANOVA was applied at the $\mathrm{P}<0.05$ level. The resulted data was further analyzed by applying Post Hoc Test to find out significant difference between the means at the $\mathrm{P}<0.05$ level. In one way ANOVA, some results were significant but Post Hoc test did not showed significant difference. 


\section{Results and discussion}

Table 1 and 2 shows effect of leaf leachates of R. communis and $V$. negundo on vegetative and reproductive traits and biomass of $M$. capitata respectively. Highest plant height [PH] and girth in control gradually decreased as concentration increased. Length of primary root was found to be more in T1 of $R$. communis than control while T2 of V. negundo had more inhibitory effect on primary root. Inhibitory effect of $V$. negundo on secondary root was maximum in T4 which then followed by T1. All treatments had significant effect on RS [root lateral spread] and DDR [depth of deepest root]. Mean of DDR/RS, DDR/PH and root: shoot ratio was significantly different among the treatments. Nodes/plant were significantly reduced $[\mathrm{P}=0.000]$ in all treatments over control. Except for $\mathrm{T} 1 \mathrm{of} V$. negundo, branches were not produced in other potted M. capitata. Highest number of leaves found in control while lowest in T1 and T3 of R. communis and $V$. negundo respectively. There was gradual and significant decrease in inflorescence/plant $[\mathrm{F}=5.33, \mathrm{P}=0.004]$, flowers/plant [F=3.72, $\mathrm{P}=0.020]$, fruits/plant and seeds/plant at all concentrations of leaf leachates of $R$. communis while leaf leachates were found to be more inhibitory and significantly reduced all reproductive traits $[\mathrm{P}=0.000]$. Biomass was significantly decreased in different treatments. T3 of $R$. communis had minimum inhibitory effect on fresh weight of root and shoot. Leaf leachates of $V$. negundo had shown significant reduction of biomass in all treatments over control. Except for few parameters [Table 1 and 2], all results were significant at $\mathrm{P}<0.05$ level.

Synthetic herbicides used to control many weeds; causing environmental pollution moreover they are non biodegeradable. With the increase in awareness about limitations of these synthetic chemicals, in recent times trend of using green control or biopesticides derived from plant kingdom is in practice. Invasive weeds are a topic of research because of their threat to biodiversity and environment. To control these invasives use of mechanical, chemical and biological control have been and are in use. Instead of using insects as biocontrol on weeds, use of other plant species to control non native invasives might be more ecofriendly. It may also possible that medicinal plants contain more bioactive compounds than other plants. To combat the hazardous effects of synthetic herbicides on environment, allelopathic properties of medicinal plants might be helpful to discover new natural herbicides for sustainable agriculture [15]. Many plant species including medicinal plants are able to produce and release secondary metabolites [bioactive compounds] into the environment and are capable of suppressing the growth of other plants [16].

Plant height of M. capitata has been reduced over control by all concentrations of leaf leachates of $R$. communis as well as $V$. negundo. Reduction in plant height might be due to effect of allelochemicals on gibberellins synthesis, the hormone responsible for cell elongation in turn plant height. Present findings are in line with findings of Gantayet et al., [17]. Root architecture of invasive was also affected by all treatment except in T1 of $R$. communis was not effective on length of primary root. Along with many effects it also includes decrease in plant growth by phenolic compounds [18]. The inhibitory effect of foliar spray was dosage dependent. Same trend was revealed by negative allelopathic effect caused by smooth Amaranth aqueous extracts on number of developed leaves, stem length, delayed flowering and total dry matter of red bean, white bean and pinto bean [19]. Number of nodes, branches and leaves per plant was highly reduced by all concentration of leaf leachates of all donors over control except in T3 of $R$. communis found least effective on branches while no branching was observed in M. capitata but seen in T1 of $V$. negundo. Inhibition of these growth parameters might be due to inhibitory influence of allelochemicals in synthesis of gibberellin, auxin and other growth hormones [20]. Yarnia et al., [21] reported reduction in plant height, leaf area, shoot and root dry weighs of Amaranthus retroflexus by 5 to $20 \%$ leaf extract of sorghum. The herbicidal potential of the foliar application of the isolated compounds from Sterculia foetida were inhibited seed germination, shoot and root length as well caused defoliation in Calotropis gigantea(R.Br.), Parthenium hysterophorus L., Datura metel L. and Tridax procumbens L. [22]. Defoliation has been also reported in M. capitata by foliar application of leaf leachates of $V$. negundo as well as $R$. communis in higher doses.

A significant reduction in reproductive traits including inflorescence, flowers, fruits and seeds per plant over control was observed by application of leaf leachates of different concentrations of $R$. communis and V. negundo. The inhibition was concentration dependent. Findings of Ramgunde and Chaturvedi [23], indicated that the vegetative and reproductive growth ofCassia uniflora was significantly inhibited at all concentration $[\mathrm{T} 1=5 \%, \mathrm{~T} 2=10 \%, \mathrm{~T} 3=15 \%$ and $\mathrm{T} 4=20 \%]$ of aqueous leaf leachates of $R$. communis and $V$. negundo when compared to control. These findings are in line with results of present study. 
Ramgunde and Chaturvedi / GSC Biological and Pharmaceutical Sciences 2019, 06(02), 108-114

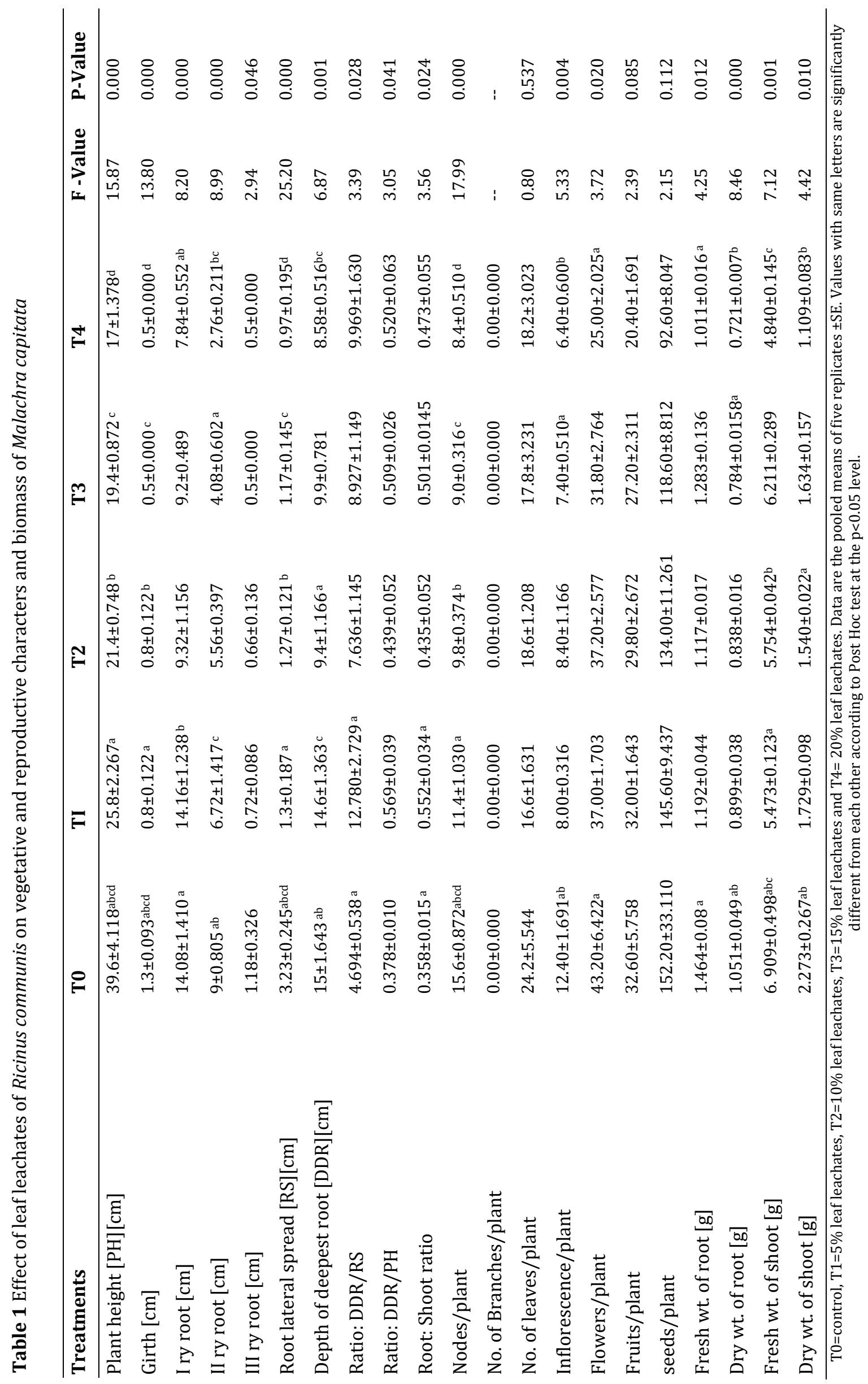


Ramgunde and Chaturvedi / GSC Biological and Pharmaceutical Sciences 2019, 06(02), 108-114

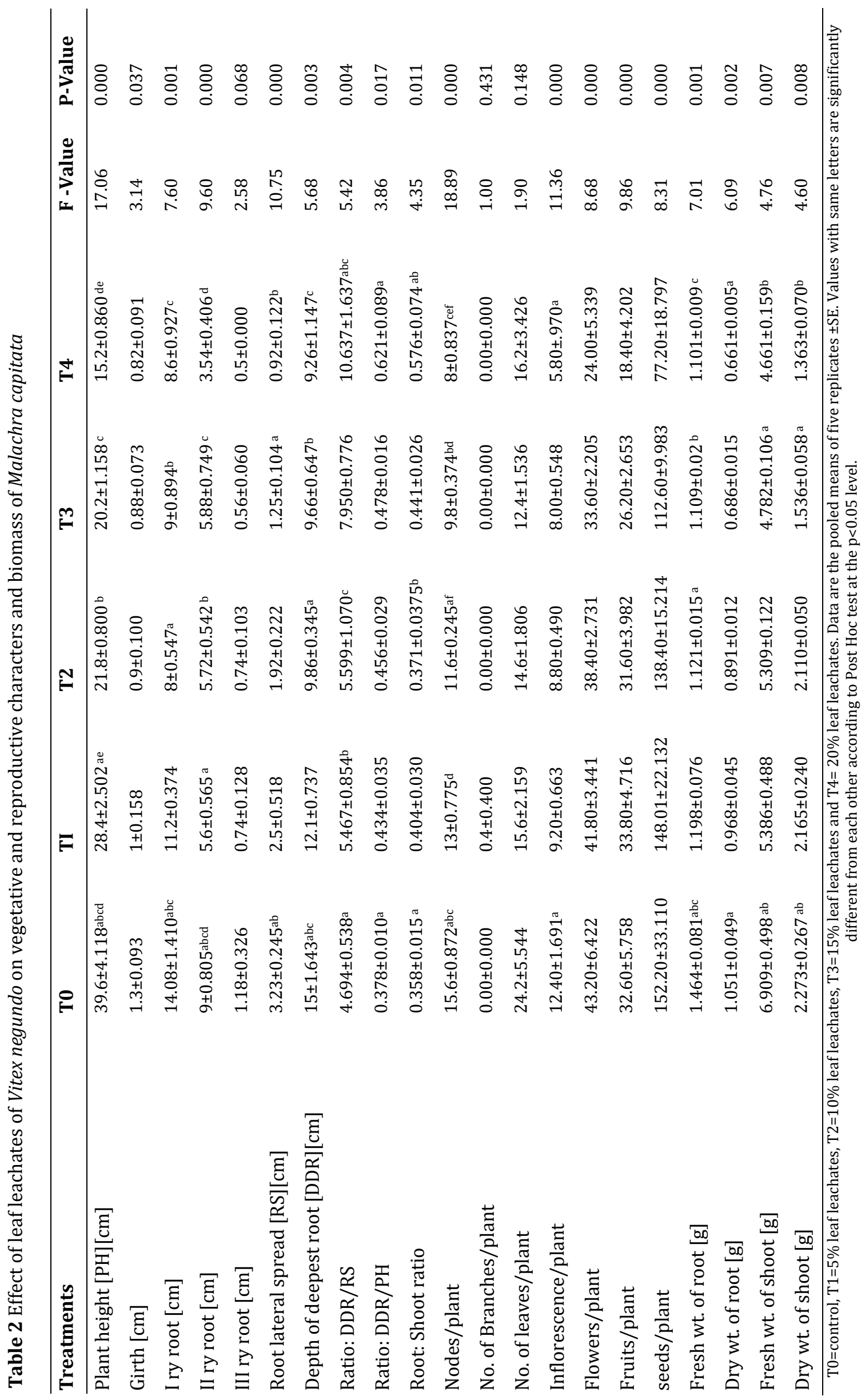


The allelochemicals might be involved in reducing reproductive traits of treated invasives by leaching of allelochemicals into the soil and affecting physiological processes involving in flower, fruit and seed formation. Components of yield [production of number of heads per plant, production of seeds per head, weight of seeds, seed yield per plant] of niger [Guizotia abyssinica] were decreased by leaf litter dust of Lantana camara [17]. In green house experiment, the powder and extract of $R$. communis significantly inhibited height, leaf area, dry weight and amount of chlorophyll of pigweed and the inhibitory effect was dosage dependent, higher the concentration, strongest the inhibitory effect [24].

\section{Conclusion}

In conclusion higher concentration of leaf leachates inhibit various growth parameters hence, further investigations needed to isolate and identify such growth inhibitors from leaves of $R$. communis and $V$. negundo and formulate natural or green control for invasive weed management strategy over synthetic or chemical control.

\section{Compliance with ethical standards}

\section{Acknowledgments}

We are grateful to Dr. (Mrs.) Rekha Sharma, UGC, Academic Staff College, Rashtrasant Tukadoji Maharaj Nagpur University, Nagpur for providing help in statistical analysis of results of this research work.

\section{Disclosure of conflict of interest}

We declare that there is no conflict of interest between us and we are solely responsible for the contents and writing of this research paper.

\section{References}

[1] Pimentel D, McNair S, Janeka J, Wightman J, Simmonds C, O’Connell, C, Wong E, Russel L, Zern J, Aquino T and Tsomondo T. [2001]. Economic and environmental threats of alien plant, animal and microbe invasions. Agr. Ecosyst.Environ, 84, 1-20.

[2] Kushwaha VB and Maurya S. [2012]. Biological utilities of Parthenium hysterophorus. Journal of Applied Natural Science, 4[1], 137-143.

[3] Ray P and Gour HN. [2012]. Integrated management of Parthenium hysterophorus L. [Asteraceae]: a weed of worldwide significance. Indian Society of Mycology and Plant Pathology, 5, 605-632.

[4] Heap IM. [2016]. International Survey of Herbicide Resistant Weeds. Available online at www.weedscience.org.

[5] Dayan FE, Cantrell CL and Duke SO. [2009]. Natural products in crop protection. Bioorganic \& Medicinal Chemistry, 17[12], 4022-4034.

[6] Reddy C. [2008]. Catalogue of invasive alien flora of India. Life Science Journal, 5[2], 84-89.

[7] Reddy CS, Bagyanarayana G, Reddy KN and Vatsavaya SR. [2008]. Invasive alien flora of India. National Biological Information Infrastructure. http://www.gisinetwork.org/

[8] Sodaeizadeh H, Rafieiolhossaini M, Havlik J and Van Damme P. [2009]. Allelopathic activity of different plant parts of Peganum harmala L. and identification of their growth inhibitors substances. Plant Growth Regulation, 59[3], 227-236.

[9] Lakshmamma P and Prayaga L. [2006]. Identifying the sources of tolerance for drought in Castor, Ricinus communis L. Journal of Oilseeds Research, 33[3], 348-352.

[10] Raoof M and Yasmeen M. [2006]. Aetiology, epidemiology and management of Botrytis grey mold of Castor, Ricinus communis L. A review. Journal of Oilseeds Research, 23[2], 144-150.

[11] Ogunniyi DS. [2006]. Castor oil: a vital industrial raw material. Bioresource Technology, 97, 1086-1091.

[12] Islam MA, Yaakob Z, Anuar N, Primandari SRP and Osman M. [2011], Physiochemical properties of Jatropha curcas seed oil from different origins and candidate plus plants [CPPs]. Journal of American Oil Chemists Society, 89, 293-300. 
[13] Ghayal N, Padhey A and Dhumal K. [2010]. Larvicidal activity of invasive weeds Cassia uniflora and Synedrella nodiflora. International Journal of Pharma and Biosciences, 1[3], 1-10.

[14] Kapoor RT. [2011]. Bioherbicidal Potential of Leaf-residue of Hyptis suaveolens on the Growth and Physiological Parameters of Parthenium hysterophorus L.Current Research Journal of Biological Sciences, 3[4], 341-350.

[15] Khanh TD, Elzaawely AA, Chung IM, Ahn JK, Tawata S.and Xuan TD. [2007]. Role of allelochemical for weed management in rice. Allelopathy Journal, 19, 85-96.

[16] Ahmad S, Arfan M, Khan AL, Ullah R, Hussain J, Muhammad Z, Khan R, Khan N and Watanabe N. [2011]. Allelopathy of Teucrium royleanum Wall. Ex Benth. From Pakistan. Journal of medicinal plants research, 5[5], 765-772.

[17] Gantayet PK, Lenka KC and Padhy B. [2011]. Vegetative growth and yield response of niger [Guizotia abyssinica] to leaf-litter dust of Lantana camara. The Bioscan, 6(2), 207-210.

[18] Barkosky RR and Einhellig FA. [2003]. Allelopathic interference of plant-water relationships by parahydroxybenzoic acid. Botanical Bulletin- Academia Sinica Taipei, 44, 53-58.

[19] Rouhollah A, Ghanepour S and Movahedpour F. [2013]. Morpho-physiological and phenological changes induced by smooth amaranth allelopathic effects in various types of dry bean. International Journal of Agriculture and Crop Sciences, 5[2], 120-124.

[20] Beffa R, Martin HV and Pilet PE. [1990]. Invitro oxidation of indoleacetic acid by soluble auxin oxidases and peroxidases from maize roots. Plant Physiology, 100, 485-491.

[21] Yarnia M, Benam KMB and Tabrizi FME. [2009]. Allelopathic effects of sorghum extracts on Amaranthus retroflexus seed germination and growth. Journal of Food Agriculture and Environment, 7, 770-774.

[22] Usha Rani P, Rajasekharreddy P and Nagaiah K. [2011]. Allelopathic effects of Sterculia foetida [L.] against four major weeds. Allelopathy Journal, 28 [2], 179-188.

[23] Ramgunde V and Chaturvedi A. [2016]. Allelopathic effect of Ricinus communis L. and Vitex negundo L. on morphological attributes of invasive alien weed: Cassia uniflora Mill. IRA-International Journal of Applied Sciences [ISSN 2455-4499], 3[3], 438-447.

[24] Marzieh SN, Razmjoo J, Kraimmojeni H, Sharifnabi B, Amini H and Bahrami F. [2014]. Assessment of some medicinal plants for their allelopathic potential against redroot pigweed (Amaranthus retroflexus). Journal of plant protection research, 54 [1], 90-95.

\section{How to cite this article}

Ramgunde V and Chaturvedi A. (2019). Allelopathic effect of some plants on morphological attributes of invasive alien weed: Malachra capitata (L.)L. GSC Biological and Pharmaceutical Sciences, 6(2), 108-114. 